\title{
Estudo de desenvolvimento de Viguiera robusta Gardn., uma Asteraceae do cerrado ${ }^{1}$
}

\author{
PATRICIA G. C. RUGGIERO² e LILIAN B. P. ZAIDAN²,3
}

(recebido em 07/03/96; aceito em 04/07/96)

\begin{abstract}
Developmental studies in Viguiera robusta Gardn., an Asteraceae from the cerrado). The purpose of this study was to add new information about physiological aspects of herbaceous plants from the cerrado. Plants of Viguiera robusta grown from seeds (achenes) were maintained under controlled photoperiodic conditions, and vegetative growth and flowering were observed during the first life cycle; sprouting was also quantified after senescence and during the subsequent growth period. The achenes germinated better under continuous light at $30^{\circ} \mathrm{C}$ and $20 / 30^{\circ} \mathrm{C}$, and the viability was maintained during 12 months with the seeds kept at $5^{\circ} \mathrm{C}$ in glass flasks. The growth parameters used, shoot length, leaf number, dry and fresh mass were not significantly different among the photoperiods tested, the least growth response appearing under $8 \mathrm{~h}$ photoperiod. Flowering was first induced in shorter photoperiods but occurred also in the longer ones; flowering plants were also observed when long-short day were given. Plants under $8 \mathrm{~h}$ - photoperiod presented a higher number of developed capituli. Young plants show opposite leaves which are alterned to alternate leaves during plant growth. This change in phyllotaxis could not be related to flower induction. When flowering occurs, liberation of lateral buds is observed. These buds form new shoots, specially under short-days. Senescence of the aerial parts is followed by sprouting, which is independent of the photoperiodic treatment applied to the plants but is probably better related to the biochemical/physiological conditions of the reserve underground organ.
\end{abstract}

RESUMO - (Estudos de desenvolvimento de Viguiera robusta Gardn., uma Asteraceae do cerrado). Com o objetivo de se conhecer alguns aspectos da fisiologia de plantas do componente herbáceo da vegetação de cerrado, foram estudados aspectos do desenvolvimento de Viguiera robusta. As plantas, obtidas a partir de sementes (aquênios), foram mantidas sob condições fotoperiódicas controladas, acompanhando-se seu crescimento vegetativo e floração, no subseqüente período de crescimento. Os aquênios germinaram melhor sob luz constantes e às temperaturas de $30^{\circ} \mathrm{C}$ e $20 / 30^{\circ} \mathrm{C}$ permanecendo viáveis após 12 meses de armazenamento a $5^{\circ} \mathrm{C}$ em frascos de vidro fechados. Sob fotoperíodo de $8 \mathrm{~h}$ houve menor crescimento vegetativo. A floração ocorre inicialmente nos fotoperíodos mais curtos e, no decorrer do tempo, também nos fotoperíodos mais longos; sob dias longos-curtos a floração também foi constatada. Plantas em fotoperíodo de $8 \mathrm{~h}$ apresentaram maior número de capítulos desenvolvidos. Plantas jovens têm folhas opostas, havendo depois o aparecimento de folhas alternas, não estando esta alteração na filotaxia relacionada com a indução da floração. A ocorrência da floração provoca a liberação de gemas laterais, que formam novos ramos, especialmente nas plantas sob tratamento fotoperiódico de 8 h. Após a senescência da parte aérea, ocorre nova brotação, independente do tratamento fotoperiódico aplicado, estando esse processo provavelmente mais relacionados às condições bioquímicas e fisiológicas do órgão subterrâneo de reserva do que às condições fotoperiódicas de crescimento.

Key words - Flowering, growth, photoperiodism, cerrado, Viguiera robusta

\section{Introdução}

A vegetação de cerrado possui como componente predominante as plantas herbáceas, sendo a família Asteraceae a mais freqüente em número de gêneros e espécies (Mantovani 1983). Estudo sobre esta vegetação têm demonstrado que representantes da família Asteraceae acumulam polímeros de frutose (Figueiredo-Ribeiro et al. 1986, Carvalho \& Dietrich 1993, Tertuliano \& Figueiredo-Ribeiro 1993), o que antes havia sido encontrado principalmente em gramíneas e cereais de regiões temperadas. Por tal, sugeriu-se que os

1. Trabalho relizado com auxílio da Fapesp (Proc.94/2670-0).

2. Seção de fisiologia e Bioquímica, Instituto de Botânica, Caixa Postal 4005, 01061-970 São Paulo, SP, Brasil.

3. Bolsista do CNPq. frutanos atuariam como crioprotetores, conferindo resistência ao frio, além de seu papel de carboidratos de reserva (Hendry 1987). Existem indicações de que os frutanos podem ter alguma função no processo de regulação osmótica dessas espécies. Os frutanos são encontrados principalmente em ordens consideradas mais evoluídas (Figueiredo-Ribeiro 1993), sendo acumulados, por exemplo, na forma de inulina, principalmente em órgão de reserva.

Viguiera robusta, Asteraceae, tribo Heliantheae, é uma espécie herbácea perene, nativa de cerrado sendo encontrada nessas formações vegetais do estado de São Paulo. Possui raízes tuberosas que acumulam frutanos, principalmente sob a forma de cristais de inulina que podem ser identificados em cortes transversais sob luz polarizada (Tertuliano \& Figueiredo-Ribeiro 1993). Os frutanos podem variar quanto à composição e ao 
conteúdo, de acordo com o ciclo de desenvolvimento da planta, as mudanças sazonais de temperatura e outros fatores ambientais, como já foi demonstrado para Viguiera discolor (Isejima et al. 1991) e Vernonia herbacea (Carvalho \& Dietrich 1993).

Segundo Montavani \& Martins (1988), no cerrado de Moji Guaçu (SP), a floração da maioria das espécies é sincronizada e ocorre entre novembro e abril, coincidindo com a espécie de maior pluviosidade, temperaturas mais altas e fotoperíodos mais longos. Mesmo não havendo grandes variações de temperatura e fotoperíodo natural no decorrer do ano, já foi demonstrada a sensibilidade de algumas espécies tropicais a oscilações destes fatores ambientais, como Stevia rebaudiana (Zaidan et al. 1980), Hyptis brevipes (Zaidan et al. 1991), Viguiera discolor (Isejima et al. 1991), Bidens gardneri (Klein et al. 1992) e Vernonia cognata (Cesarino \& Zaidan 1995).

O objetivo do presente trabalho foi analisar a germinação, o crescimento e a floração de plantas de Viguiera robusta, obtidas a partir de sementes (aquênios) e colocadas sob condições fotoperiódicas controladas, visando contribuir para o conhecimento das plantas do componente herbáceo da vegetação de cerrado.

\section{Material e métodos}

As plantas de Viguiera robusta utilizadas foram obtidas a partir da germinação de sementes (aquênios) coletadas originalmente em área de cerrado no município de Itirapina ( $\left.22^{\circ} 15^{\prime} \mathrm{S} ; 47^{\circ} 50^{\prime} \mathrm{W}\right)$, no estado de São Paulo (SP, col. Zaidan 24). Germinação - Os aquênios recém-coletados foram colocados em placas de Petri de $9 \mathrm{~cm}$ de diâmetro com papel de filtro umedecido e mantidas em germinadores (BOD-FANEM) sob luz branca $\left(437 \mu \mathrm{W} . \mathrm{cm}^{-2} \cdot \mathrm{s}^{-1}\right.$ na altura das placas) ou escuro constantes nas seguintes condições: $20^{\circ} \mathrm{C}, 25^{\circ} \mathrm{C}, 30^{\circ} \mathrm{C}$ e temperatura alternada de $20 / 30^{\circ} \mathrm{C}$ (apenas sob luz branca). Em todos os tratamentos, foram utilizadas 200 sementes sob luz e 200 sementes (50 por placa) sob escuro; nesse último caso, as placas foram colocadas dentro de dois sacos plásticos pretos. O número de sementes germinadas foi verificado a cada três dias. As que permaneceram no escuro foram observadas sob luz verde de segurança (Labouriau 1966).

Crescimento e floração - Os aquênios foram armazenados em frascos de vidro, a $5^{\circ} \mathrm{C}$, até a época de utilização. Estes foram semeados em caixas contendo terra de mata umedecida. Posteriormente, as plantas foram transferidas para vasos individuais contendo o mesmo substrato. As plantas foram colocadas num primeiro experimento em fotoperíodos de $8,14 \mathrm{e}$ $20 \mathrm{~h}$, entre dezembro e julho, e num segundo experimento, nos fotoperíodos de $8,12,16,20,8 / 20$ e $20 / 8 \mathrm{~h}$, entre agosto e dezembro. Em todos os tratamentos, as plantas receberam $8 \mathrm{~h}$ de luz natural em casa de vegetação e suplementação de luz, quando necessária, em câmaras individuais, com controle automático do período de iluminação, fornecida por lâmpadas incandescentes e fluorescentes, com fluxo de energia de $3,5 \mu \mathrm{E} \cdot \mathrm{m}^{-2} \cdot \mathrm{s}^{-1}$, conforme detalhado em Klein et al. (1992). Nos tratamentos 8/20 e 20/8h, as plantas permaneceram 45 dias no primeiro fotoperíodo e 82 dias na outra condição fotoperiódica.

Semanalmente, foram tomadas medidas de comprimento do ramo principal e contado o número de folhas ou de nós, para análise do crescimento, e observados o número de capítulos, o número de flores e o número de dias decorridos até o aparecimento do botão floral, para análise da floração. A observação do botão floral foi feita a olho nu. Com os dados obtidos foi calculada a porcentagem de plantas floridas.

Foram feitas observações quanto à alteração da filotaxia e à liberação das gemas laterais entre $35^{\circ}$ e $84^{\circ}$ dias de tratamento. A brotação de gemas laterais foi acompanhada nas plantas sob condições fotoperiódicas controladas, considerando-se gemas basais aquelas formadas no terço inferior do ramo e apicais as que surgiram no terço superior do ramo. Quando gemas apicais e basais surgiram num mesmo ramo, constituíram um grupo isolado.

A velocidade de crescimento $\left(\mathrm{cm} \cdot \mathrm{dia}^{-1}\right)$ foi calculada a partir dos dados semanais de comprimento do ramo. Foram tomados os dados de massa de matéria fresca e seca ao final do período de observação (206 e 127 dias), quando os órgãos subterrâneos foram analisados quanto à presença e ao tipo de raízes espessadas.

Foi feita análise de variância ao nível de 5\% de probabilidade pelo teste de Tukey (Snedecor 1962). Para os dados de alteração da filotaxia, foram calculados a média e o desvio padrão e para os demais dados de floração, apenas a média.

\section{Resultados}

Germinação - Foi verificado que, sob luz, a germinação de aquênios recém-coletados de $V$. robusta é lenta, sendo iniciada cerca de 50 dias após o início da embebição. Por volta de $100^{\circ}$ dia, apenas $20 \%$ dos aquênios germinaram. Sob escuro constante, foi baixa a germinação. Sob luz, valores mais altos de porcentagem de germinação foram obtidos (tabela 1), especialmente com alternância de temperatura $\left(20^{\circ} \mathrm{C} / 30^{\circ} \mathrm{C}\right)$ e à temperatura constante de $30^{\circ} \mathrm{C}$. Os aquênios de $V$. robusta permaneceram viáveis por pelo menos 12 meses após coletados e armazenados a $5^{\circ} \mathrm{C}$ (dados não mostrados).

Crescimento vegetativo - Em fotoperíodo de 8, 14 e $20 \mathrm{~h}$, (primeiro experimento) observou-se que tanto o comprimento do ramo principal (figura 1A) como

Tabela1. Porcentagem de sementes de V. robusta germinadas após 137 dias sob tratamento com diferentes condições de temperaturas sob luz e escuro.

\begin{tabular}{ccc}
\hline \multirow{2}{*}{ Temperatura } & \multicolumn{2}{c}{ Condição de luz } \\
\cline { 2 - 3 } & luz & escuro \\
\hline $20^{\circ} \mathrm{C}$ & 49,5 & 3,5 \\
$25^{\circ} \mathrm{C}$ & 39,0 & 2,0 \\
$30^{\circ} \mathrm{C}$ & 70,5 & 15,5 \\
$20 / 30^{\circ} \mathrm{C}$ & 79,5 & - \\
\hline
\end{tabular}



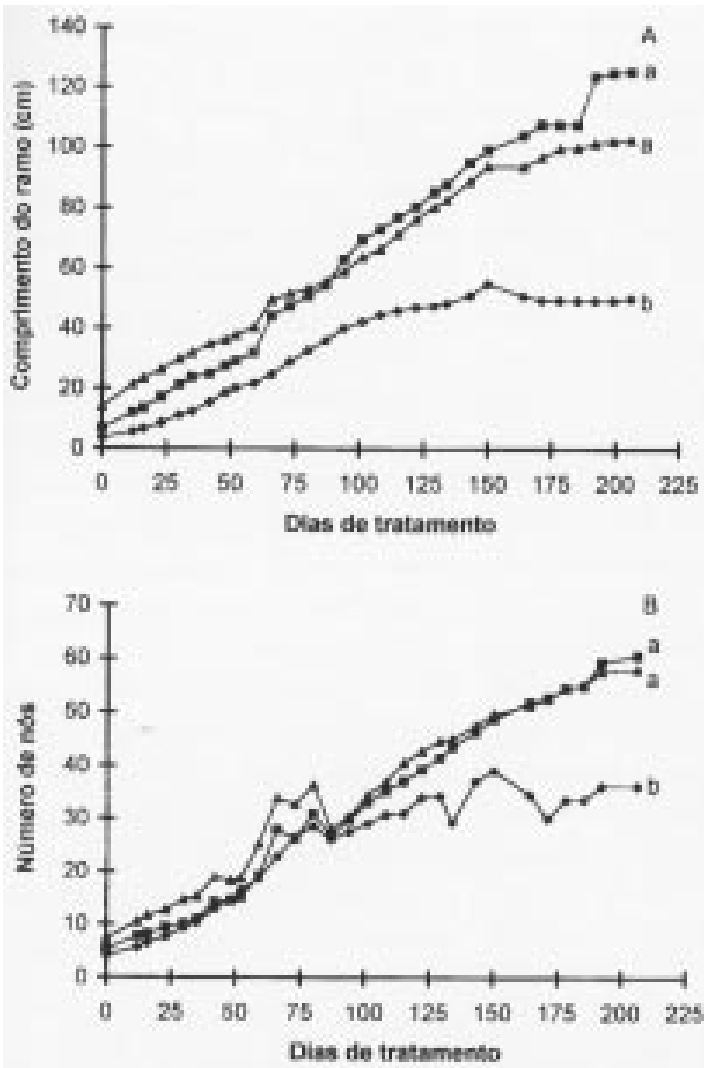

Figura 1. Crescimento de plantas de V. robusta em fotoperíodos de $8 \mathrm{~h}(\bullet), 14 \mathrm{~h}(\boldsymbol{\square})$ e $20 \mathrm{~h}(\boldsymbol{\Delta})$, durante 206 dias. A. Comprimento do ramo; B. Número de nós. Letras comparam os diferentes tratamentos num mesmo dia.

o número de nós (figura 1B) foram menores nas plantas em $8 \mathrm{~h}$, não havendo diferenças entre os tratamentos de 14 e $20 \mathrm{~h}$, ao final do período de observação. As velocidades médias de crescimento para comprimento, calculadas entre os dias 37 e 127, foram $0,23 \mathrm{~cm} \cdot \mathrm{dia}^{-1} \mathrm{em} 8 \mathrm{~h}, 0,57 \mathrm{~cm} \cdot \mathrm{dia}^{-1} \mathrm{em} 14 \mathrm{~h} \mathrm{e}$ $0,43 \mathrm{~cm} \cdot \mathrm{dia}^{-1} \mathrm{em} 20 \mathrm{~h}$.

No segundo experimento, quando um número

Tabela 2. Valores médios \pm desvio padrão de massa de matéria fresca e seca da parte aérea de plantas de $V$. robusta que receberam tratamentos fotoperiódicos de 8, 14 e 20 horas. Dados obtidos após 206 dias de cultivo (primeiro experimento, dezembro a julho).

\begin{tabular}{ccc}
\hline Fotoperíodo & $\begin{array}{c}\text { Massa de matéria } \\
\text { fresca }(\mathrm{g})\end{array}$ & $\begin{array}{c}\text { Massa de matéria } \\
\text { seca }(\mathrm{g})\end{array}$ \\
\hline $8 \mathrm{~h}$ & $5,17 \pm 0,72$ & $1,82 \pm 0,18$ \\
$14 \mathrm{~h}$ & $15,93 \pm 1,65$ & $5,24 \pm 0,60$ \\
$20 \mathrm{~h}$ & $11,66 \pm 4,00$ & $3,46 \pm 1,32$ \\
\hline
\end{tabular}
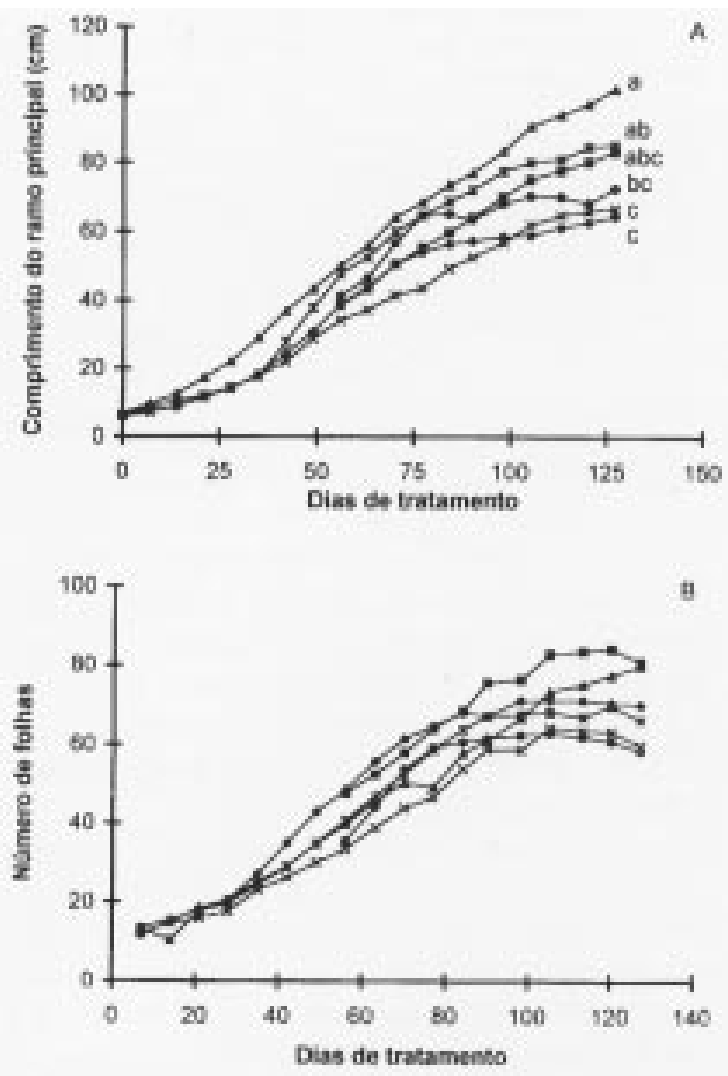

Figura 2. Crescimento de plantas de $V$. aff. robusta em fotoperíodos de $8 \mathrm{~h}(\bullet), 12 \mathrm{~h}(\mathbf{\Delta}), 16 \mathrm{~h}(\times), 20 \mathrm{~h}(*), 8 / 20 \mathrm{~h}(\boldsymbol{\square})$ e 20/8 h $(\bullet)$. Letras comparam os diferentes tratamentos num mesmo dia. A. Comprimento do ramo; B. Número de folhas.

maior de fotoperíodos foi utilizado, aqueles que se mostraram menos favoráveis ao crescimento vegetativo foram: 8 e $16 \mathrm{~h}$, apesar de serem estatisticamente semelhantes aos tratamentos de $20 / 8$ e de $8 / 20$ h (figura $2 \mathrm{~A}$ ). Pela análise estatística feita com os dados do dia 127 , os tratamentos 20/8, $8 / 20$ e $20 \mathrm{~h}$ foram semelhantes entre si. No tratamento com $12 \mathrm{~h}$ de fotoperíodo houve o maior comprimento do ramo principal. Os dados de número de folhas dos dias 120 e 127, quando analisados, não apresentaram diferenças estatisticamente significativas (figura 2B).

Com relação às massas de matéria fresca e seca, puderam ser observadas algumas diferenças entre os tratamentos (tabelas 2 e 3).

Quando se compararam apenas os três fotoperíodos (8,14 e 20, primeiro experimento), observou-se que sob $14 \mathrm{~h}$ de luz, a massa de matéria fresca e seca foi cerca de três vezes maior que em $8 \mathrm{~h}$ 
Tabela 3. Massa de matéria fresca e seca da parte aérea das plantas de $V$. robusta ao final de 127 dias de cultivo (segundo experimento, agosto a dezembro).

\begin{tabular}{ccl}
\hline Fotoperíodo & $\begin{array}{c}\text { (1) Massa } \\
\text { fresca }(\mathrm{g})\end{array}$ & $\begin{array}{c}\text { (2) Massa } \\
\text { seca }(\mathrm{g})\end{array}$ \\
\hline $8 \mathrm{~h}$ & $7,029 \mathrm{~d}$ & $1,745 \mathrm{c}$ \\
$8 / 20 \mathrm{~h}$ & $11,801 \mathrm{abc}$ & $2,741 \mathrm{ab}$ \\
$12 \mathrm{~h}$ & $12,253 \mathrm{ab}$ & $2,983 \mathrm{a}$ \\
$16 \mathrm{~h}$ & $8,370 \mathrm{~cd}$ & $1,944 \mathrm{bc}$ \\
$20 \mathrm{~h}$ & $12,788 \mathrm{a}$ & $3,089 \mathrm{a}$ \\
$20 / 8 \mathrm{~h}$ & $8,834 \mathrm{bcd}$ & $2,190 \mathrm{abc}$ \\
\hline
\end{tabular}

(1) DMS 5\% Tukey $=3,486$

(2) DMS 5\% Tukey $=0,926$

(tabela 2). Nos outros fotoperíodos ensaiados (segundo experimento), verificou-se, em geral, que dias mais longos promoveram o acúmulo de massa fresca e seca. As diferenças entre os vários fotoperíodos deste experimento foram mais evidentes em termos de massa de matéria fresca (tabela 3).

Floração - No primeiro experimento, as plantas tratadas com fotoperíodo de $8 \mathrm{~h}$ floresceram anteriormente às de 14 e $20 \mathrm{~h}$, apresentando $100 \%$ de plantas com botão floral no $211^{\circ}$ dia de cultivo. Apenas $25 \%$ das plantas sob fotoperíodo de $14 \mathrm{~h}$ apresentaram flores no $281^{\circ}$ dia de cultivo. Já as plantas sob fotoperíodo de $20 \mathrm{~h}$ apresentaram resposta intermediária, em termos de porcentagem de plantas floridas e de tempo para iniciar o processo (figura 3.)

No segundo experimento, o tratamento que apresentou maior porcentagem de plantas induzidas foi o de $20 / 8 \mathrm{~h}$. Neste tratamento, no $90^{\circ}$ dia de

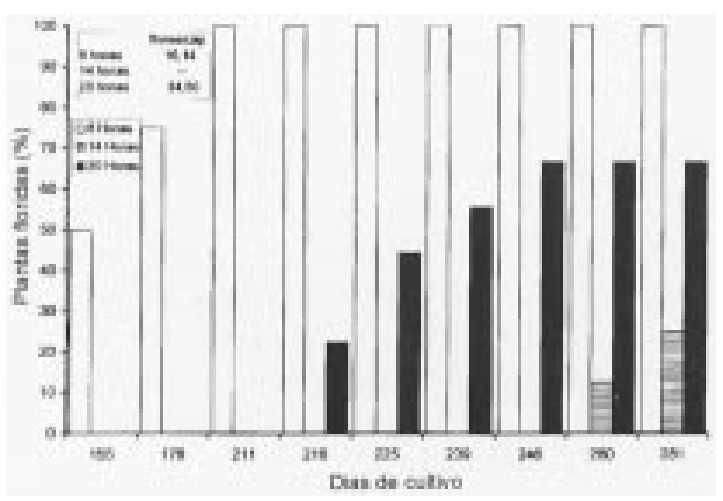

Figura 3. Floração em plantas de V. robusta em três tratamentos fotoperiódicos, $8 \mathrm{~h} ; 14 \mathrm{~h}$ e $20 \mathrm{~h}$. Média de flores por capítulo por tratamento. tratamento, $90 \%$ das plantas apresentaram botão floral iniciando (figura 4). No entanto, a floração em termos de porcentagem de plantas floridas foi antecipada pela exposição ao fotoperíodo constante de $8 \mathrm{~h}$. Valores altos, em termos de porcentagem de plantas floridas, foram obtidos sob fotoperíodos de 20 e $16 \mathrm{~h}$. As plantas em fotoperíodo de $8 \mathrm{~h}$ apresentaram maior número de capítulos por planta e maior porcentagem de capítulos desenvolvidos. As plantas do tratamento $8 / 20 \mathrm{~h}$ tinham o menor número de capítulos iniciados por planta, não ocorrendo capítulos desenvolvidos (tabela 4). Nos tratamentos de $12 \mathrm{~h}$ e de $8 / 20 \mathrm{~h}$ ocorreram as menores porcentagens de plantas floridas e estas floresceram mais tardiamente, em relação às dos demais tratamentos (figura 4).

Quanto ao desenvolvimento do botão, os tratamentos que apresentaram maiores porcentagens finais de plantas induzidas (20/8 e $20 \mathrm{~h}$ ) estavam entre os menos favoráveis ao desenvolvimento das inflorescências (figura 4, tabela 4). No tratamento de $12 \mathrm{~h}$ de fotoperíodo, pouco favorável à indução, houve o mesmo número de flores por capítulo que em $16 \mathrm{~h}$. Os fotoperíodos de 8 e $16 \mathrm{~h}$ foram os mais favoráveis aos desenvolvimento do botão floral.

Brotação - Durante o primeiro ciclo de desenvolvimento das plantas, observou-se uma alteração na filotaxia. As plantas jovens apresentaram folhas opostas. No decorrer do desenvolvimento, a disposição das folhas passa a ser alterna. A figura 5 mostra que esta mudança ocorreu com menor intensidade no tratamento com $16 \mathrm{~h}$ de fotoperíodo. Esta alteração foi observada a partir do dia 35 e o número de plantas com filotaxia alterna foi aumentando de forma gradual e contínua. O número médio de pares de folhas opostas formados até o início da mudança de filotaxia foi quantificado (tabela 5).

Aos 63 dias, a liberação de gemas laterais ocorreu em todos os tratamentos fotoperiódicos com exceção de 20/8h. Maior intensidade de brotação foi detectada nos tratamentos de 8 e $8 / 20$ h (tabela 6). Considerando todas as plantas do tratamento de $8 \mathrm{~h}$ observou-se que, no que se refere à posição dessas gemas, $50 \%$ apenas apresentaram gemas basais em desenvolvimento, $10,7 \%$ apenas gemas apicais e $25 \%$ das plantas apresentaram liberação de gemas basais e apicais simultaneamente. Em fotoperíodo de $8 \mathrm{~h}$, do total de plantas com gema laterais em 


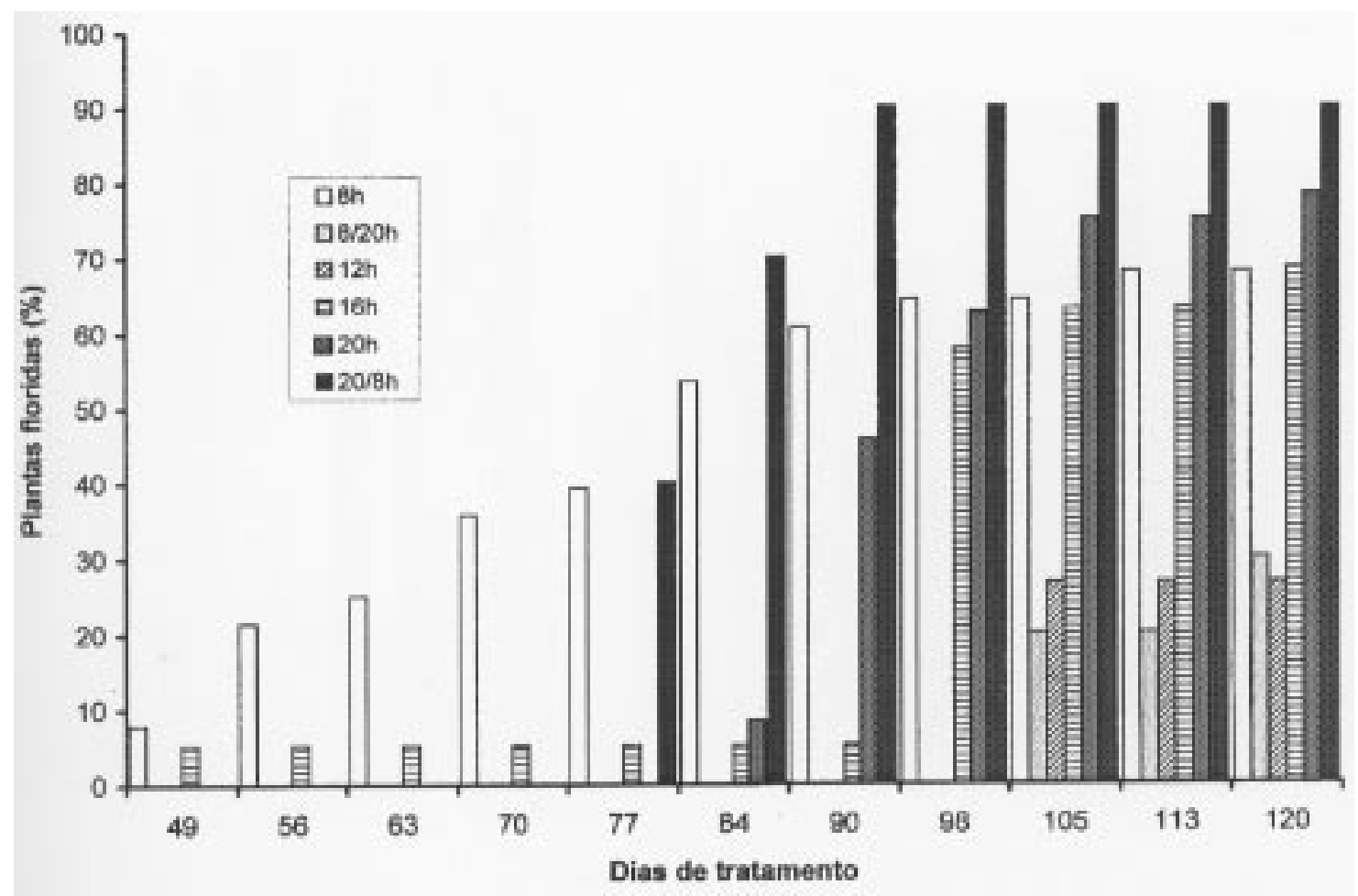

Figura 4. Floração em plantas de V. robusta submetidas aos tratamentos fotoperiódicos de 8 h, 12 h, 16 h, 20 h, 8/20 h e 20/8 h.

desenvolvimento (24 plantas), 50\% encontravam-se em processo de floração. Foi verificado que, nas plantas em floração sob fotoperíodo de $8 \mathrm{~h}$, todas apresentaram liberação das gemas laterais nas seguintes proporções: $50 \%$ mostraram gemas na base e no ápice do ramo, concomitantemente; $25 \%$ apenas gemas basais e $25 \%$ apenas gemas apicais.

As gemas laterais liberadas nas plantas sob fotoperíodos controlados desenvolvem-se,

Tabela 4. Floração em V. robusta. Número médio de capítulos iniciados por planta (No. de cap/planta), número médio de flores por capítulo desenvolvido (No. de fl/cap) e porcentagem de capítulos que se desenvolveram em relação ao número total de capítulos iniciados (\% de cap. desenvol.) em cada tratamento fotoperiódico (segundo experimento, agosto a dezembro).

\begin{tabular}{cccc}
\hline Fotoperíodo & $\begin{array}{c}\text { № de } \\
\text { cap./planta }\end{array}$ & № de fl./cap. & $\begin{array}{c}\text { \% de cap. } \\
\text { desenvol. }\end{array}$ \\
\hline $8 \mathrm{~h}$ & 4,3 & 35,5 & 61,6 \\
$8 / 20 \mathrm{~h}$ & 1,7 & --- & 0,0 \\
$12 \mathrm{~h}$ & 2,5 & 51,7 & 30,0 \\
$16 \mathrm{~h}$ & 3,3 & 51,7 & 39,5 \\
$20 \mathrm{~h}$ & 3,5 & 35,0 & 23,8 \\
$20 / 8 \mathrm{~h}$ & 2,9 & 46,5 & 7,7 \\
\hline
\end{tabular}

formando ramos. Estes resultados estão apresentados na tabela 7. Quanto à porcentagem de plantas com ramos, após 127 dias, em todos os tratamentos ocorreram valores altos, com exceção de $12 \mathrm{~h}$ (apenas 20\%). Os maiores valores foram obtidos nos tratamentos de 8, 20/8 e 8/20 h. Apesar da alta porcentagem de plantas com ramificações, o tratamento fotoperiódico de $8 / 20 \mathrm{~h}$ foi o que apresentou menor número de ramos por planta. A liberação das gemas laterais no tratamento de 20/8h ocorreu mais tardiamente (dados não mostrados).

Após a floração e a formação dos aquênios, as plantas apresentaram sinais de senescência na parte aérea. Os órgãos aéreos foram retirados e observou-se o aparecimento de novos ramos. Segundo os resultados apresentados na tabela 8 , nota-se alta porcentagem de plantas rebrotadas em todos os tratamentos fotoperiódicos. E quanto ao número médio de ramos por plantas, os valores obtidos foram semelhantes, não havendo diferenças entre os tratamentos.

As plantas que não rebrotaram apresentaram o órgão subterrâneo de reserva em processo de 


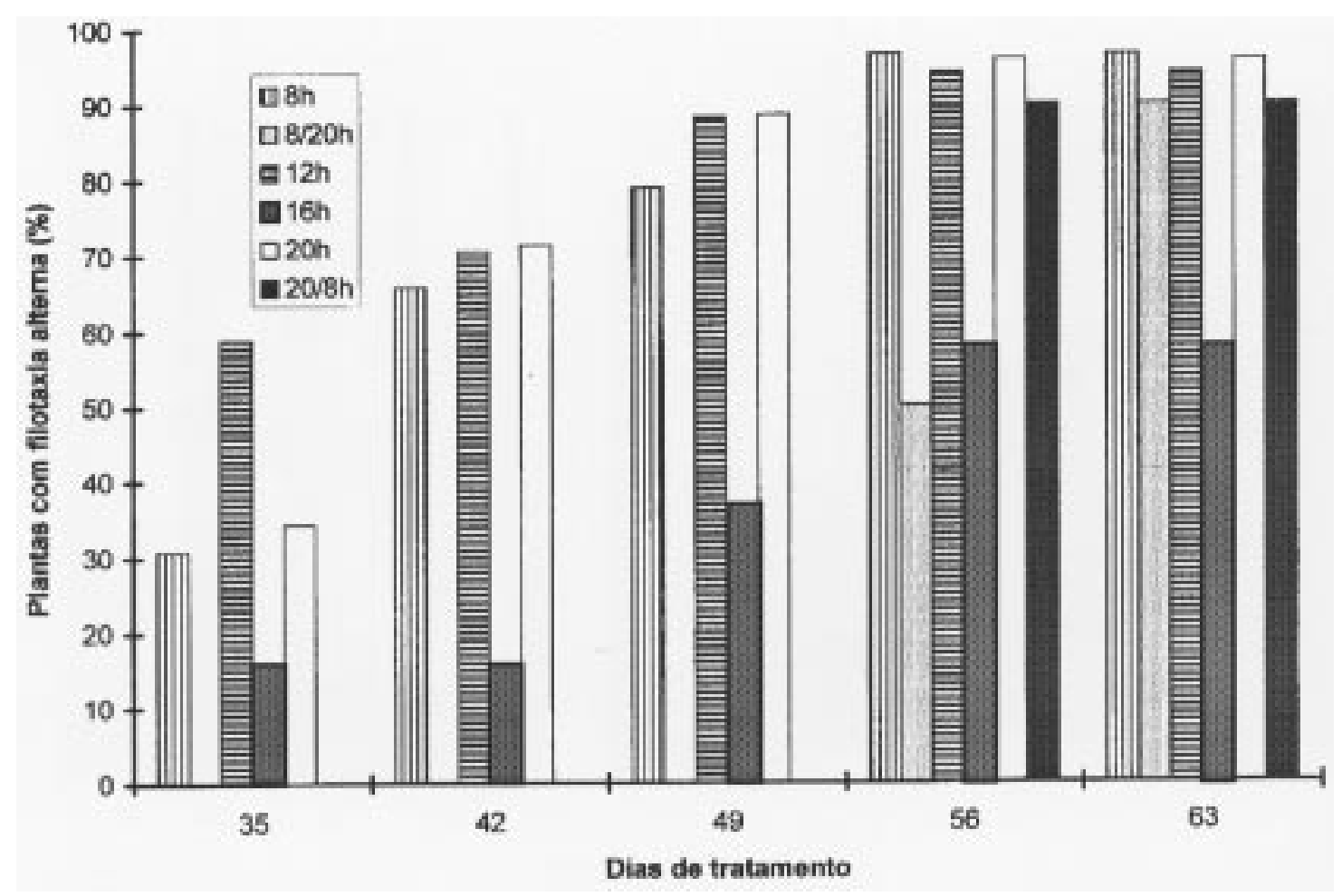

Figura 5. Ocorrência de folhas alternas em plantas de V. robusta crescidas sob condições fotoperiódicas controladas.

decomposição. Foi possível notar que as raízes espessadas destes indivíduos tinham tamanho maior do que os espessamentos encontrados nos indivíduos que rebrotaram. Ainda, as plantas rebrotadas apresentaram formação abundante de raízes secundárias na forma de raízes absorventes, localizadas no fundo do vaso.

\section{Discussão}

Aparentemente, as sementes (aquênios) de Viguiera robusta são fotoblásticas positivas e

Tabela 5. Número (média \pm desvio padrão) de pares de folhas formados até o início da filotaxia alterna, em plantas de $V$. robusta mantidas em diferentes condições fotoperiódicas.

\begin{tabular}{cc}
\hline Fotoperíodo & № de pares de folhas \\
\hline $8 \mathrm{~h}$ & $12,37 \pm 2,04$ \\
$8 / 20 \mathrm{~h}$ & $15,50 \pm 3,72$ \\
$12 \mathrm{~h}$ & $10,60 \pm 1,80$ \\
$16 \mathrm{~h}$ & $13,09 \pm 2,11$ \\
$20 \mathrm{~h}$ & $11,86 \pm 1,48$ \\
$20 / 8 \mathrm{~h}$ & $11,00 \pm 0,92$ \\
\hline
\end{tabular}

apresentam maior porcentagem de germinação sob temperaturas alternadas de $20 / 30^{\circ} \mathrm{C}$ e temperatura constante de $30^{\circ} \mathrm{C}$. A maneira como foram contadas as sementes germinadas não permitiu a análise estatística dos resultados. O aquênio de $V$. aff. robusta apresenta tegumento permeável à água. $\mathrm{O}$ atraso no início da germinação pode ter sido ocasionado por um processo de pós-maturação, como observado anteriormente por Rizzini (1973 in Felippe \& Silva 1984) em Annona crassiflora que apresentou tegumento permeável à água e apenas começou a germinar após 200 dias do início da

Tabela 6. Porcentagem de plantas de V. robusta apresentando liberação de gemas laterais após 63 dias sob condições fotoperiódicas controladas.

\begin{tabular}{cc}
\hline Fotoperíodo & Porcentagem de plantas \\
\hline $8 \mathrm{~h}$ & 85,71 \\
$8 / 20 \mathrm{~h}$ & 80,00 \\
$12 \mathrm{~h}$ & 23,53 \\
$16 \mathrm{~h}$ & 26,31 \\
$20 \mathrm{~h}$ & 25,71 \\
$20 / 8 \mathrm{~h}$ & 0,00 \\
\hline
\end{tabular}


embebição. O autor sugeriu que isto teria ocorrido devido ao fato da semente possuir embrião indiferenciado.

Num primeiro experimento, com relação à floração, V. robusta pareceu comportar-se como uma planta quantitativa de dias curtos, confirmando os resultados preliminares mostrados por Cesarino et al. (1994). Uma outra espécie de Viguiera, V. discolor, também encontrada em regiões de cerrado do estado de São Paulo, foi considerada por Isejima et al. (1991) como de dias curtos qualitativa, florescendo apenas em fotoperíodos inferiores a $12 \mathrm{~h}$. Sob fotoperíodo de $8 \mathrm{~h}$, nos dois períodos do ano em que foram realizados os experimentos, $V$. robusta apresentou baixo crescimento em termos de comprimento do ramo e número de nós, alta porcentagem de plantas floridas, com as plantas respondendo mais cedo do que nos outros tratamentos fotoperiódicos. No período de julho a dezembro, quando a temperatura estava em

Tabela 7. Número de plantas de $V$. aff robusta com ramificações (№ pl.c/ram.), porcentagem de plantas com ramificações (\% pl.c/ ram.) 127 dias após o início dos tratamentos fotoperiódicos (127 dias).

\begin{tabular}{cccc}
\hline Fotoperíodo & $\begin{array}{c}\text { No pl. no } \\
\text { início do } \\
\text { tratamento }\end{array}$ & № pl. c/ ram. & $\%$ pl. c/ ram. \\
\hline $8 \mathrm{~h}$ & $30^{*}$ & 27 & 96,4 \\
$8 / 20 \mathrm{~h}$ & 10 & 7 & 70,0 \\
$12 \mathrm{~h}$ & $20^{*}$ & 3 & 20,0 \\
$16 \mathrm{~h}$ & $20^{*}$ & 12 & 66,7 \\
$20 \mathrm{~h}$ & $30^{*}$ & 14 & 60,8 \\
$20 / 8 \mathrm{~h}$ & $10^{*}$ & 6 & 75,0 \\
\hline
\end{tabular}

* Tratamentos em que houve perda de indivíduos.

Tabela 8. Brotação em plantas de $V$. robusta sob diferentes condições fotoperiódicas. Número de ramos por planta (média \pm desvio padrão) e porcentagem de plantas rebrotadas por tratamento.

\begin{tabular}{ccc}
\hline Fotoperíodo & ramos/planta & $\begin{array}{c}\% \text { de plantas } \\
\text { rebrotadas }\end{array}$ \\
\hline $8 \mathrm{~h}$ & $5,6 \pm 3,2$ & 78,6 \\
$8 / 20 \mathrm{~h}$ & $4,0 \pm 1,6$ & 90,0 \\
$12 \mathrm{~h}$ & $4,0 \pm 2,0$ & 100,0 \\
$16 \mathrm{~h}$ & $4,3 \pm 2,5$ & 83,3 \\
$20 \mathrm{~h}$ & $2,8 \pm 1,8$ & 95,6 \\
$20 / 8 \mathrm{~h}$ & $4,0 \pm 1,7$ & 70,0 \\
\hline
\end{tabular}

elevação, o fotoperíodo de $8 \mathrm{~h}$ levou à formação de mais capítulos e eles se desenvolveram melhor do que nos outros tratamentos fotoperiódicos. Sob os fotoperíodos de 16 e $20 \mathrm{~h}$, foram observadas taxas elevadas de crescimento vegetativo e alta porcentagem de plantas floridas. Sob fotoperíodos de 12 e $14 \mathrm{~h}$, as plantas apresentaram alto crescimento vegetativo e baixa porcentagem de plantas com flores. Salisbury \& Ross (1992) denominaram de ambifotoperiódicas as plantas cuja floração é quantitativamente inibida por fotoperíodos intermediários. Foi verificado que a resposta ao fotoperíodo de $16 \mathrm{~h}$, quanto ao crescimento e à porcentagem final de plantas floridas, foi semelhante à de $8 \mathrm{~h}$.

Os resultados preliminares obtidos por Cesarino et al. (1994) em relação ao desenvolvimento das inflorescências sugeriram que $V$. robusta poderia requerer dias curtos seguidos de dias longos ou vice-versa para que houvesse desenvolvimento completo das flores do capítulo. Espécies que apresentam esse tipo de resposta são menos comuns que as de dias curtos ou de dias longos (Schwabe \& Wimble 1976). No entanto, Coutinho \& Dionello (1980) descreveram o comportamento de floração em Melinis minutiflora, o conhecido capim-gordura, invasora freqüente em regiões de cerrado, como sendo uma planta de dias longos-curtos. Quando a floração de $V$. robusta foi estudada em plantas mantidas sob várias condições fotoperiódicas, inclusive $8 / 20 \mathrm{~h}$ e $20 / 8 \mathrm{~h}$, entre julho e agosto (figura 4), observou-se alta porcentagem de plantas floridas em 20/8 h à semelhança do que ocorreu nos outros tratamentos de dias longos ( $20 \mathrm{~h}$ e $16 \mathrm{~h})$. Por outro lado, em 20/8 h poucos capítulos se desenvolveram (tabela 4). A diferença encontrada para o número de flores por capítulo sob fotoperíodo de $8 \mathrm{~h}$, entre o primeiro e o segundo experimento (figura 3 e tabela 4), pode estar relacionada à época em que os experimentos foram realizados: o primeiro, entre dezembro e julho, quando as temperaturas foram diminuindo no decorrer do experimento e o segundo, de agosto a dezembro, quando as temperaturas estavam aumentando. Segundo Vince-Prue (1975), pequenas variações de temperatura podem causar alterações na resposta de floração em várias espécies, mostrando que a resposta fotoperiódica está intimamente relacionada ao fator temperatura. 
Através de observações feitas no campo, nota-se que $V$. robusta floresce entre os meses de novembro e abril, comportamento já descrito por Mantovani \& Martins (1988) para as espécies herbáceo-subarbustivas do cerrado da Estação Experimental e Reserva Biológica de Moji Guaçu, SP.

No estado de São Paulo, a variação do fotoperíodo está entre 10,5 horas e 13,5 horas (Vianello \& Alves 1991). Assim, fotoperíodos de $8 \mathrm{~h}$ e os acima de $13,5 \mathrm{~h}$ poderiam ser condições estressantes de crescimento que, em consequência, provocariam respostas diferente das observadas em condições naturais.

No processo de floração em $V$. robusta, a transformação da gema vegetativa em floral se dá, inicialmente, na gema apical. Este fato ocasiona um aumento rápido de comprimento do ramo principal devido ao escapo floral e, posteriormente, uma redução do crescimento do ramo, durante a fase de desenvolvimento do botão. Durante a floração também há liberação das gemas laterais, provavelmente em decorrência da quebra da dominância apical a partir da transformação da gema apical vegetativa em botão floral. Deve ocorrer uma diminuição na produção de auxina ao longo do ramo, em direção à base da planta, em oposição a um aumento na concentração de giberelinas que promovem o desenvolvimento destas gemas. Estas se desenvolvem em ramos laterais nos quais há, em grande parte, formação de flores. Nas plantas cultivadas há mais tempo em canteiros experimentais da Seção de Fisiologia e Bioquímica de Plantas, observa-se que a cada ciclo a planta rebrota, apresentando vários ramos, e cada um deles desenvolve ramos laterais que vão produzir flores.

Analisando-se os dados obtidos para crescimento e floração, nota-se que o decréscimo na razão de crescimento a partir do momento em que as plantas começam a florescer é seguido de sinais de senescência da parte aérea. O período de dormência, característico de herbáceas perenes do cerrado, é comum em parada de crescimento, senescência e abscisão da parte aérea, que rebrota com mais vigor quando começa o período de chuvas. Este comportamento é mencionado de um modo geral por Mantovani \& Martins (1988) e verificado experimentalmente em Viguiera discolor, Vernonia herbacea e Gomphrena macrocephala (Isejima et al. 1991; Carvalho \& Dietrich 1993; Vieira \&
Figueiredo-Ribeiro 1993). Coutinho et al. (1982), também descreveram este comportamento como uma adaptação fenológica ao ambiente do cerrado, sugerindo estar relacionado ao fotoperíodo.

Numa determinada fase de desenvolvimento das plantas, notou-se alteração na filotaxia. Esta alteração poderia estar relacionada ao processo de floração e ser indicativo de uma possível maturidade para responder à indução floral; alterações na morfologia e na disposição das folhas podem indicar mudanças no desenvolvimento vegetativo para o floral (Klein et al. 1992). No entanto, com os dados aqui mostrados não foi possível afirmar se este fato ocorre em $V$. robusta. No tratamento de 8 h houve alta porcentagem de plantas com a filotaxia alterada e alta porcentagem de plantas com flor; em $12 \mathrm{~h}$ de fotoperíodo, ocorreu alta porcentagem de plantas com a filotaxia alterada e baixa porcentagem de plantas em floração. Ainda, no tratamento de $8 / 20 \mathrm{~h}$ observou-se alta porcentagem de plantas induzidas e plantas com a filotaxia alterada, porém com prejuízo no desenvolvimento do botão.

Ainda, com relação à filotaxia comparada ao crescimento vegetativo das plantas nos diferentes tratamentos, não pode ser feita nenhuma relação direta, uma vez que sob 8 e $12 \mathrm{~h}$ o crescimento foi muito diferente. É possível, portanto, que a alteração na filotaxia seja apenas um fato relacionado ao desenvolvimento da espécie, não estando diretamente relacionado ao processo de floração.

$\mathrm{Na}$ rebrota após o período de dormência, notou-se que as plantas tendem a ter mais vigor e maior número de ramos. Ambos os processos, liberação de gemas laterais e ramificação, foram mais intensos nas plantas sob $8 \mathrm{~h}$ de fotoperíodo. Também foi observado, na rebrota da parte aérea, que as raízes espessadas diminuem de tamanho e desenvolvem raízes secundárias finas. Estas observações mostram que os espessamentos devem realmente ter função de armazenamento de carboidratos (frutanos, no caso) enquanto as raízes secundárias devem ser responsáveis pela absorção de água e nutrientes, com desenvolvimento concomitante ao da parte aérea.

Agradecimentos - Ao Dr. Gil M. Felippe, pelas sugestões e leitura crítica do manuscrito. 


\section{Referências bibliográficas}

CARVALHO, M. A. M. \& DIETRICH, S. M. C. 1993. Variations in fructan content in the underground organs of Vernonia herbacea (Vell.) Rusby at different phenological phases. New Phytol, 123:735-740.

CESARINO, F \& ZAIDAN, L.B.P. 1995. Crescimento e desenvolvimento de Vernonia cognata Less. em três condições fotoperiódicas. Resumos do XLVI Congresso Nacional de Botânica p.241.

CESARINO, F., ZAIDAN, L. B. P. \& RUGGIERO, P. G. C. 1994. Crescimento e floração em Viguiera robusta sob três condições fotoperiódicas. Resumos do XLV Congresso Nacional de Botânica p.194.

COUTINHO, L.M. \& DIONELLO, S.B. 1980. O capim-gordura (Melinis minutiflora Beanv.) uma espécie de dia longo-curto para florescer. Revta brasil. Bot. 3:59-62.

COUTINHO, L. M., DE VUONO, Y. S. \& LOUSA, J. S. 1982. Aspectos ecológicos do fogo no cerrado IV - A época da queimada e a produtividade primária líquida epigéia do estrato herbáceo subarbustivo. Revta brasil. Bot. 5:37-41.

FELIPPE, G.M. \& SILVA, J.C.S. 1984. Estudos de germinação em espécies do cerrado. Revta brasil. Bot. 7:157-163.

FIGUEIREDO-RIBEIRO, R.C.L. 1993. Distribuição, aspectos estruturais e funcionais dos frutanos, com ênfase em plantas herbáceas do cerrado. R. Bras. Fisiol. Veg. 5:203-208.

FIGUEIREDO-RIBEIRO, R.C.L., DIETRICH, S.M.C., CHU, E. P., CARVALHO, M.A. M., VIEIRA, C. C. J., GRAZIANO, T. T. 1986. Reserve carbohydrates in underground organs of native Brazilian plants. Revta brasil. Bot. 9:159-166.

HENDRY, G. 1987. The ecological significance of fructan in a contemporary flora. New Phytol. 106:201-216.

ISEJIMA, E. M., FIGUEIREDO-RIBEIRO, R. C. L. \& ZAIDAN, L. B. P. 1991. Fructan composition in adventitious tuberous roots of Viguiera discolor Baker (Asteraceae) as influenced by daylength. New Phytol. 119:149-154.

KLEIN, A.L., ZAIDAN, L.B.P. \& FELIPPE, G.M. 1992. Flowering and heterophylly in Bidens gardneri Baker. Revta brasil. Bot. 15:139-144.
LABOURIAU, L.F.G. 1966. Revisão da situação da ecologia vegetal nos cerrados. An. Acad. Bras. Ciênc. 38:5-58 (suplemento).

MANTOVANI, W. 1983. Composição e similaridade florística, fenologia e espectro biológico do Cerrado da Reserva Biológica de Mogi-Guaçu, São Paulo. Tese de mestrado, Universidade Estadual de Campinas, Campinas.

MANTOVANI, W. \& MARTINS, F.R. 1988. Variações fenológicas das espécies do cerrado da Reserva Biológica de Mogi-Guaçu, estado de São Paulo. Revta. Brasil. Bot. 11: 101-112.

SALISBURY, F.B. \& ROSS, C.W. 1992. Plant Physiology. Wadsworth Publishing Co., Belmont.

SCHWABE, W.W. \& WIMBLE, R.H. 1976. Control of flower initiation in long-day and short-day plants - A common model approach. In Perspectives in experimental biology (N. Sunderland, ed.). Pergamon Press, Oxford, p.41-57.

SNEDECOR, G.W. 1962. Statistical Methods. The Iowa State University Press, Iowa.

TERTULIANO, M. F. \& FIGUEIREDO-RIBEIRO, R.C.L. 1993. Distribution of fructan polymers in herbaceous species of Asteraceae from cerrado. New Phytol. 123:741-749.

VIEIRA, C.C.J. \& FIGUEIREDO-RIBEIRO, R.C.L. 1993. Fructose-containing carbohydrates in the tuberous root of Gomphrena macrocephala St. -Hil (Amaranthaceae) at diferent phenological phases. Plant Cell Envir. 16: 919-928.

VIANELLO, R. L. \& ALVES, A. R. 1991. Meteorologia básica e aplicações. Imprensa Universitária, Viçosa.

VINCE PRUE, D. 1975. Photoperiodism in plants. Mc Graw-Hill, London.

ZAIDAN, L. B. P., DIETRICH, S. M. C. \& FELIPPE, G. M. 1980. Effect of photoperiod on flowering and stevioside content in plants of Stevia rebaudiana Bertoni. Jap. J. Crop Sci. 49: 569-574.

ZAIDAN, L.B.P., DIETRICH, S.M.C. \& SCHWABE, W.W. 1991. Effects of temperature and photoperiod on flowering in Hyptis brevipes. Physiol. Plant. 81:221-226. 